\title{
A STUDY ON DIFFERENT DIETARY PRACTICES AT FARMERS' FIELD FOR RAISING LAYER CHICKS IN DEEP LITTER BROODING SYSTEM
}

\author{
A. K. DAS ${ }^{1 *}$, N. GHOSH ${ }^{2}$, N. K. TUDU ${ }^{3}$, S. DATTA $^{1}$ \\ C. $\mathrm{GHOSH}^{4}$, A. ROY ${ }^{5}$ AND S. MUKHERJEE ${ }^{6}$ \\ Howrah Krishi Vigyan Kendra \\ Jagatballavpur, Howrah-711 408 \\ West Bengal, India
}

\begin{abstract}
Most farmers traditionally raise layer chicks at small scale when artificially hatched out using litter based basket-brooders but with different dietary practices which were subjected to refinement through this investigation. The major farmers' practice feeding with broken rice and/or crushed wheat often supplemented with commercial mash was termed as redefined farmers' practice (RFP) when replaced with a diet containing broken rice (50\%), crushed wheat $(30 \%)$ and commercial broiler mash $(20 \%)$. Few farmers' practice feeding with commercial mash and very few farmers' practice with feed ingredientsmix were termed as TO1 and TO2, respectively. Thirty tribal farmers were equally divided in RFP, TO1 and TO2 groups for raising day old chicks (ten RIR by each farmer) with different dietary practices. The data were analyzed by least squares analysis of variance and means of body weights, weight gains, FCR and BCR at different weeks and periods of age were estimated. The highest $(\mathrm{P}<0.05)$ body weights and weight gains throughout the ages and better FCR at younger age were observed in the TO1 group followed by the RFP and TO2; but better FCR at grower age and better BCR estimates was recorded in the RFP followed by either TO2 or TO1. The investigation thus could suggest that the redefined farmers' practice would be the most economic at farmers' field for raising layer chicks in deep litter.
\end{abstract}

Key words: BCR, Body weight gains, FCR, Field level dietary practices, RIR chicks

Due to the growing population, limited

necessary to develop a comprehensive resources, poverty and hidden hunger, it is economic program for sustainable

\footnotetext{
*Corresponding Author

${ }^{1}$ Department of Animal Genetics and Breeding, West Bengal University of Animal and Fishery Sciences, W. B.

${ }^{2}$ Deptartment of Livestock Production and Management, WBUAFS, W. B.

${ }^{3}$ Department of Veterinary Anatomy and Histology, WBUAFS, W. B.

${ }^{4}$ Department of Livestock Farm Complex, F/o Veterinary and Animal Sciences, WBUAFS, Mohanpur, Nadia, W. B.

${ }^{5}$ Murshidabad Krishi Vigyan Kendra, Murshidabad, W. B.

${ }^{6}$ Howrah Krishi Vigyan Kendra, Jagatballavpur, Howrah-711 408, W. B.
} 
production system (Naghshi et al., 2014). Poultry production is gaining popularity in the developing countries due to its role in bridging the protein malnutrition, economic empowerment of the resource poor segment of the society and also fits well in the farming systems commonly practiced (King'ori, 2011). High yielding few layer chickens such as RIR, White Leghorn and dual purpose Black Australorp have got much appreciated and acclimatized in rural backyard poultry rearing system. Most farmers raise layer chicks at small scale (1015 chicks) using basket-brooders and/or mosquito-net covered semi sunny outdoor space thus protecting from predators. Chicks are provided ad lib. water and different diets as practiced only at day times. After attaining two to three weeks of age, chicks are allowed on free-range foraging. Due to recent squeezing foraging area or limited resources in the backyard system, birds cannot either grow well or perform at its optimum productivity level. Only broken rice and/or crushed wheat feeding often supplemented with minute quantity of commercial mash is a dietary practice followed by most of the farmers. Feeding with commercial broiler mash being at ease available in market (broiler meat shop) is another dietary practice followed by few farmers. Extraneous vitamin-mineral mixture is sometimes supplemented but often in sub-standard doses. As commercial feed costs in increasing trend and FAO focuses on increasing the feed base production systems to locally available feed resources in developing countries (Sansoucy, 1993), an on-farm trial (OFT) was undertaken to refine different dietary practices at farmers' field for raising layer chicks in deep litter brooding system.

\section{MATERIALS AND METHODS}

The investigation was carried out during FY: 2015-16 at Khardah-Bamunpara village of Shankarhati-II GP under Jagatballavpur block, Howrah district (WB). Thirty tribal farmers were selected and subjected to use bamboo-made big sized and wide basket-brooder with mosquito-net covering for raising layer chicks at small scale using $2 \frac{1}{2}$ inch deep improved litter materials of saw dust, husk and chopped paddy straw mixed at 20:5:1 ratio (Das et al., 2016) and an over-hanging electric bulb $(40 \mathrm{~W})$ at an appropriate height depending on ambient temperature. The most common farmers' practice was redefined as herein called redefined farmers' practice (RFP) when replaced with a ration containing broken rice $(50 \%)$ @ Rs. 15/- per kg, crushed wheat (30\%) @ Rs. 18/- per kg and commercial broiler mash (Benpro®, 20\%) @ Rs. 40/- per kg, thus having an overall costing @ Rs. 20.90/ - per kg ration. Few farmers' practice feeding with commercial broiler mash 
(Benpro®) and very few farmers' practice feeding with feed ingredients-mix were designated as technology options 1 (TO1) and 2 (TO2), respectively. Feed ingredients-mix was prepared mixing of crushed maize-10 kg assuming market price @ Rs. 20/- per kg, broken rice-32.5 kg @ Rs. 15/- per kg, wheat bran-15 kg @ Rs. 20/- per kg, rice bran-15 kg @ Rs.3/- per $\mathrm{kg}$, deoiled crushed groundnut cake-10kg @ Rs.32/- per kg, deoiled crushed mustard cake-15 kg @ Rs.24/- per kg, LSP-1.2 kg @ Rs. 9/- per kg, DCP-900 g @ Rs. 50/per kg, salt-300 g @ Rs. 10/- perkg and vitamin-mineral mix-100 g @ Rs. 80/- per $\mathrm{kg}$ for preparation of $100 \mathrm{~kg}$ ration, having an overall costing @ Rs. 18.35/-per kg and containing $19.9 \% \mathrm{CP}, 5.4 \% \mathrm{CF}, 2.76 \mathrm{Mcal}$ $\mathrm{kg}^{-1} \mathrm{ME}, 138.8 \mathrm{C}: \mathrm{P}, 1.2 \% \mathrm{Ca}, 0.43 \% \mathrm{P}$, $0.83 \%$ Lys, $0.4 \%$ Met, $0.29 \%$ Cys and $1.5 \%$ Arg when calculated considering available reports on chemical composition and nutritive values of feed ingredients (FAO's Animal Feed Resources Information System, www.feedipedia. org). The thirty farmers were equally divided in three dietary groups (RFP, TO1 and TO2) provided with required feed or feed-mix and day old chicks (10 RIR) distributed to each farmer.
The chicks were procured from State Poultry Farm, Gobardanga, North 24 Parganas (WB), dubbed (beak trimming) to prevent fighting, and then reared onto the defined brooder at farmers' field with standard floor space and brooding temperature by adjusting the height of the hanging light. Fresh water and defined diets were provided at lib. thrice a day. The chicks were vaccinated with RD F strain at first week of age with booster dose on fourth week, fowl pox vaccine (CEVL) on sixth week and RD $\mathrm{R}_{2} \mathrm{~B}$ on eighth week of age. The chicks were provided with weighed quantity of the defined feed (diet) by each farmer. The feed residue was weighed by each farmer after each recording period, followed by notice of any mortality on specific date, if any, being accordingly weighed and noted date-wise.

The traits of live body weight (BW), live weight gain (WG), feed conversion ratio (FCR) and benefit cost ratio (BCR) were investigated at different weeks and periods of age for the chicks under the different dietary groups. Average feed intake per week was determined for each chick under each farmer from their record in feed chart considering also feed residuals and proportional feed intake by dead $\operatorname{chick}(\mathrm{s})$ 
at appropriate date to less. Weekly average weight gain was calculated for each chick under each farmer from their records of weekly individual body weights considering also mortality. Then FCR and BCR were calculated for each chick. For calculating BCR, gross return was determined assuming sale price of 4, 6 and 8 week aged chicks @ Rs. 150/-per kg live weight plus Rs. 20/- (chick's price), and gross expenditure was determined on the basis of per $\mathrm{kg}$ feed cost as incurred for the different diets, but cost involved in buying day old chicks, vaccination, brooding and management being constant for the different dietary groups was hence neglected in determining gross expenditure.

The data were analyzed by least squares analysis of variance (Harvey, 1990) taking the dietary groups as fixed effect. The least squares means were compared by Critical Difference (CD) test (Stevens, 1999).

\section{RESULTS}

The estimated least squares means of live body weights (BW), live weight gains (WG), feed conversion ratios (FCR) and benefit cost ratios (BCR) at different weeks and periods of age of RIR chicks raised under different defined dietary groups in deep litter brooding system at farmers' field were presented in Table 1. The least squares analysis of variance demonstrated that the defined three dietary groups varied significantly for various $\mathrm{BW}(\mathrm{P}<0.001)$, WG $(\mathrm{P}<0.001)$, BCR $(\mathrm{P}<0.001)$ and FCR $(\mathrm{P}<0.001$, $\mathrm{P}<0.01, \mathrm{P}<0.05)$ at different weeks and/ or periods of age except FCR at 6-8 week. The highest $(\mathrm{P}<0.05)$ body weight and weight gain estimates throughout the ages, and better FCR at younger age were obtained in the chicks under TO1 group followed by the RFP and TO2 groups, though RFP and TO2 being statistically indifferent for weight gain at $3^{\text {rd }}, 5^{\text {th }}, 6^{\text {th }}, 8^{\text {th }}$ and 4-6 week, and for FCR at $1^{\text {st }}$ and $4^{\text {th }}$ week. But better FCR at grower age was recorded in the RFP group followed by TO1 and TO2 groups at 4-6 week and by TO2 and TO1 at 6-8 week period; though the FCR estimates being statistically indifferent for RFP and TO1 at 4-6 week, and for all the dietary groups at 6-8 week. It was also evident that raising chicks under the RFP group was the most economic (having the highest BCR estimates) throughout the studied periods followed by the TO2 and TO1 groups. 
Field level dietary practices for chicks

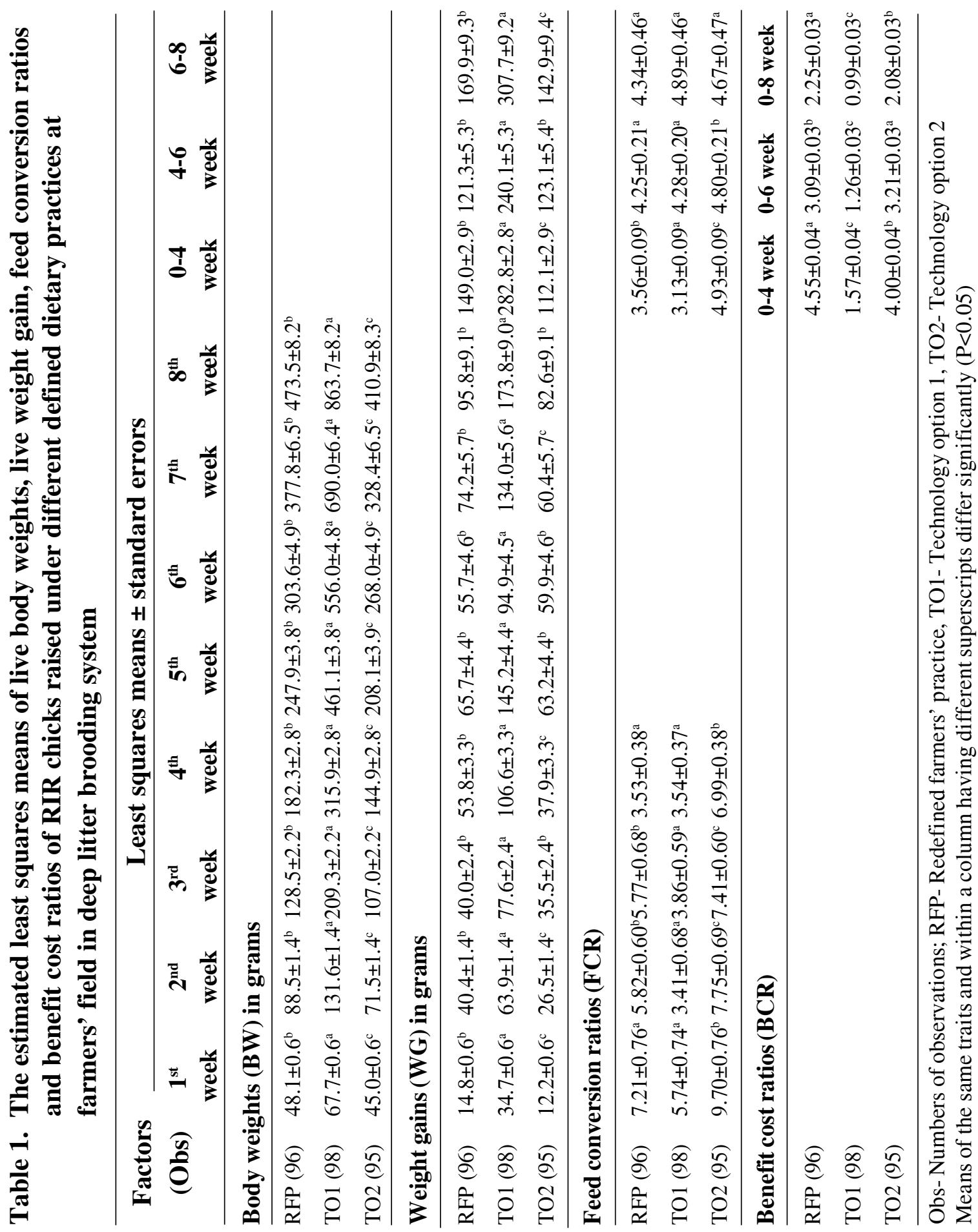




\section{DISCUSSION}

The results of this investigation were presented in ICBEAS-2017 (Das et al., 2017). The present chicks when raised under RFP and TO2 had comparable BW estimates to the reports for different feed in RIR (Das et al., 2014ab; Hassen et al., 2006) and WLH (Qadri et al., 2013; Jaya Laxmi et al., 2010). But TO1 chicks gained more body weights as like as CARIDebendra chicken (Das et al., 2014a). The WG estimates of the present RIR chicks for the periods of 0-4, 4-6 and 6-8 weeks under RFP and TO2 groups were comparable to the corresponding reports in RIR-white strain (Das et al., 2014b), whereas the chicks when raised under TO1 gained far more periodical weight gains as evident when compared to the reports in RIR lines (Das et al., 2015ab) and RIR-white strain (Das et al., 2014b). The present weekly FCR mean estimates for different dietary groups were larger (though FCR at $4^{\text {th }}$ week for RFP and TO1 being comparable) than the available reports likely in Ardennaise chicken (Lariviere et al., 2009) indicating poor efficiency of the feed. The present periodical FCR means were comparable at 0-4 weeks and also far better at 4-6 and 68 weeks as evident when compared to the reports in RIR lines (Das et al., 2015ab);

\section{REFERENCES}

Das AK, Ghosh N, Tudu NK, Roy A and Mukherjee S, 2017. Refining different though Das et al. (2014b) reported better FCR at younger age (0-4 weeks) and comparable estimates at grower age (4-6 and 6-8 weeks) in RIR-white strain. It was also evident that raising chicks under the RFP group was the most economic (having the highest BCR estimates) throughout the studied periods followed by the TO2 and TO1 groups.

It is concluded that the present investigation could suggest that layer chicks might be raised for first three weeks with commercial feed followed by redefined farmers' practice for better FCR and BCR. To judge the efficacy of this home-made feed ingredients-mix, a thorough investigation might be carried out replacing commercial broiler mash with commercial layer chick mash in the taken interventions so designed in the present study.

\section{ACKNOWLEDGEMENT}

The authors sincerely acknowledge the Director, ATARI-Kolkata for providing TSP fund to the KVK, Scientist cum Head, Howrah KVK for facilitating and the beneficiary farmers for extending their helpful hands in entire investigation process. dietary practices at farmers' field for raising layer chicks in deep litter 
brooding system. In: Proceedings of $1^{\text {st }}$ International Conference on BioResource, Environment and Agricultural Sciences (ICBEAS-2017), Palli Siksha Bhavana, Visva-Bharati Sriniketan (West Bengal), Feb 4-6, pp $10-11$

Das AK, Mukherjee S and Singh AK, 2016. Assessment of improved brooding medium for increasing hatchability of eggs by deshi broody hens. Ind Res J Ext Edu, 16(1): 68-71

Das AK, Kumar S and Rahim A, 2015a. Genetics of body conformation and feed efficiency characteristics in a control line of Rhode Island Red chicken. Iran J Appl Anim Sci, 5(4): 965-973

Das AK, Kumar S, Rahim A and Kokate LS, 2015 b. Genetic analysis of body conformation and feed efficiency characteristics in a selected line of Rhode Island Red chicken. Asian J Anim Sci, 9(6): 434-440

Das AK, Kumar S, Rahim A and Mishra AK, 2014a. Genetic variability in immunocompetenceand performance status of Rhode Island Red chicken strains and its crosses. Int $\mathbf{J}$ Bioreso Stress Manag, 5(2): 246-254

Das AK, Kumar S, Rahim A, Kokate LS and Mishra AK, 2014b. Assessment of body conformation, feed efficiency and morphological characteristics in Rhode Island Red-white strain chicken. Ind J Anim Sci, 84(9): 984-991
Harvey WR, 1990. User's guide for LSMLMW, mixed model least squares and maximum likelihood computer programme. Ohio State University (Mimeograph)

Hassen H, Neser FWC, Dessie T, de Kock A and Marle-Koster EV, 2006. Studies on the growth performance on native chicken ecotypes and RIR chicken under improved management system in Northwest Ethiopia. Livest Res Rural Devel. Available in http://www. cipav.org.co/ lrrdhome.html

Jaya Laxmi P, Gupta BR, Chatterjee RN, Sharma RP and Reddy VR, 2010. Genetic analysis of growth and production traits in IWK strain of White Leghorn. Ind J Poult Sci, 45(2): 123-126

King'ori AM, 2011. Review of the factors that influence egg fertility and hatchability in poultry. Int J Poult Sci, 10(6): 483492

Lariviere JM, Farnir F, Detilleux J, Michaux C, Verleyen V et al., 2009. Performance, breast morphological and carcass traits in the Ardennaise chicken breed. Int $\mathbf{J}$ Poult Sci, 8(5): 452-456

Naghshi H, Khojasteh S and Jafari M, 2014. Investigation the effect of different levels of azolla (Azolla pinnata) on performance and carcass characteristics of Cobb broiler chicks. Int J Farm Allied Sci, 3(1): 45-49

Qadri FS, Savaliya FP, Patel AB, Joshi RS, Hirani ND et al., 2013. Genetic study 
on important economic traits in two strains of White Leghorn chicken. Ind J Poult Sci, 48(2): 149-153

Sansoucy R, 1993. The FAO program for better utilization of local feed resources in developing countries. In: Proceedings of $7^{\text {th }}$ World Conference on Animal
Production, Edmonton, (Canada), pp 77-80

Stevens J, 1999. Canonical correlations. In: J Stevens (Ed.), Applied multivariate statistics for the social sciences. $3^{\text {rd }} \mathrm{Ed}$, Mahwah, NJ: Erlbaum, pp 429-449 